\title{
Purification and characterization of a novel immunomodulatory protein from the medicinal mushroom Trametes versicolor
}

\author{
LI Feng ${ }^{1,2}$, WEN HuaAn ${ }^{1 *}$, ZHANG YongJie $^{3}$, AN Min ${ }^{1} \&$ LIU XingZhong ${ }^{1 *}$ \\ ${ }^{1}$ Key Laboratory of Systematic Mycology and Lichenology, Institute of Microbiology, \\ Chinese Academy of Sciences, Beijing 100101, China; \\ ${ }^{2}$ Graduate University of Chinese Academy of Sciences, Beijing 100049, China; \\ ${ }^{3}$ School of Life Sciences, Shanxi University, Taiyuan 030006, China
}

Received May 12, 2010; accepted August 19, 2010; published online March 4, 2011

\begin{abstract}
Bioactive proteins represent an important group of functional agents in medicinal mushrooms. Trametes versicolor (L.) Lloyd is a mushroom frequently used in traditional Chinese medicine for its anti-tumor and immunomodulatory activities. A new immunomodulatory protein from $T$. versicolor, named TVC, was purified by ammonium sulfate precipitation, ion-exchange chromatography and gel filtration chromatography. Sodium dodecyl sulfate-polyacrylamide gel electrophoresis analysis of the purified protein revealed a single band with a molecular weight of $15.0 \mathrm{kD}$. Native polyacrylamide gel analysis revealed a band at $30 \mathrm{kD}$, indicating that TVC exists in solution as a homodimer. Isoelectric focusing showed that TVC was an acidic protein with an isoelectric point of 4.0. TVC was found to lack carbohydrate modifications (based on periodic acid/Schiff staining) and it does not agglutinate mouse red blood cells, suggesting that TVC is not a lectin-like protein. Biological activity assays demonstrated that TVC can enhance the proliferation of splenocytes, while it has no stimulatory effects on CD4 ${ }^{+}$and $\mathrm{CD} 8^{+} \mathrm{T}$ cells. TVC markedly increases the proliferation of human peripheral blood lymphocytes in a dose-dependent manner and enhances the production of both nitric oxide and tumor necrosis factor-alpha by lipopolysaccharide-induced murine macrophages. The results indicate that TVC is an immunostimulant that can boost immune response. Comparison of the $\mathrm{N}$-terminal amino acid residues and mass spectrometry results with the protein database revealed no homologous proteins.
\end{abstract}

biological activity, immunomodulatory protein, medicinal mushroom, purification, Trametes versicolor

Citation: $\quad$ Li F, Wen H A, Zhang Y J, et al. Purification and characterization of a novel immunomodulatory protein from the medicinal mushroom Trametes versicolor. Sci China Life Sci, 2011, 54: 379-385, doi: 10.1007/s11427-011-4153-2

The commonly used Chinese medicinal mushroom Trametes versicolor (L.) Lloyd has a wide range of biological activities including antiviral, antitumor, and immunomodulatory effects [1]. The polysaccharide Krestin (PSK), obtained from $T$. versicolor, has been successfully developed as a commercial product, especially for use in cancer immunotherapy. Polysaccharides are considered to be the major functional agents contained in this mushroom [2]. Bioactive proteins, however, also constitute an important group of functional agents and are attracting increasing attention

*Corresponding author (email: wenha@im.ac.cn; liuxz@im.ac.cn) because of their pharmaceutical potential [3-8]. Fungal immunomodulatory proteins (FIP) are among the best documented mushroom proteins and have useful immunomodulatory and antitumor activities. Ling Zhi-8 was the first FIP to be isolated from Ganoderma lucidum, in 1989, and it has a structure that is similar to the variable region of immunoglobulin heavy chains [9]. Ling Zhi-8 has also been revealed to be a mitogen for human peripheral blood lymphocytes and mouse splenocytes in vitro [10,11]. Ling Zhi-8 has various bioactivities, including induction of cytokine production in vivo by activating macrophages and $\mathrm{T}$ lymphocytes, reduction of antigen-induced antibody formation 
and systemic anaphylaxis, prevention of autoimmune diabetes in non-obese diabetic mice, and modification of adhesion molecule expression in immunocompetent cells [12-14]. To date, several immunomodulatory proteins have been identified from various fungi, including FIP-fve, FIP-vvo, FIP-gts, APP and PCiP, which were isolated from Flammulina velutipes, Volvariella volvacea, G. tsugae, Auricularia polytricha, and Pleurotus citrinopileatus, respectively. These proteins have characteristics and immunomodulatory activities similar to those of Ling Zhi-8 [15-19]. Thus, immunomodulatory proteins from medicinal mushrooms are good candidates for the development of new drug types for the treatment of cancer and various autoimmune diseases.

In preliminary experiments, we found that crude protein extracts from the fruiting body of $T$. versicolor had a proliferative effect on human peripheral blood lymphocytes and we speculated that a protein may be responsible for this immune activity. Here, we present a new immunomodulatory protein from $T$. versicolor, TVC, which was purified and fully characterized.

\section{Materials and methods}

\subsection{Materials and reagents}

Fruiting bodies of $T$. versicolor were obtained from a local market and were identified by Professor Zhang XiaoQing (Institute of Microbiology, Chinese Academy of Sciences, Beijing, China). Human peripheral blood lymphocytes (hPBLs), obtained from volunteers, were isolated by the Ficoll-Hypaque method and resuspended in Roswell Park Memorial Institute (RPMI) 1640 medium supplemented with $10 \%$ fetal calf serum, 100 units $\mathrm{mL}^{-1}$ penicillin, $100 \mu \mathrm{g}$ $\mathrm{mL}^{-1}$ streptomycin, $200 \mathrm{mmol} \mathrm{L}^{-1}$ L-glutamate and $10 \mathrm{mmol}$ $\mathrm{L}^{-1}$ HEPES at pH 7.3, as described by Strong et al. [20]. Murine macrophage cell line RAW 264.7 (ATCC No. TIB-71), purchased from the Cell Culture Centre of The Institute of Basic Medical Sciences, Chinese Academy of Medical Sciences, Beijing, China, was cultured in Dulbecco's Modified Eagle's medium (DMEM) supplemented with $4 \mathrm{mmol} \mathrm{L}{ }^{-1}$ L-glutamine, $1.4 \mathrm{~g} \mathrm{~L}^{-1}$ sodium bicarbonate, $4.5 \mathrm{~g} \mathrm{~L}^{-1}$ glucose, $1 \mathrm{mmol} \mathrm{L}^{-1}$ sodium pyruvate, and $10 \%$ $(\mathrm{v} / \mathrm{v})$ fetal calf serum. BALB/c mice and male SD/CD line rats were purchased from Beijing Vital River Company.

Q-Sepharose Fast Flow columns and Superdex G-75 columns were purchased from Pharmacia (Sweden). Lipopolysaccharide (LPS, E. coli, Serotype 0.55:B5) and concanavalin A were purchased from Sigma-Aldrich (USA), and fetal bovine serum (FBS) was obtained from Hyclone (USA). The Griess reagent system for detecting nitric oxide (NO) production, and methanethiosulfonate (MTS, CellTiter $96^{\circledR}$ AQueous One Solution) for detecting cell proliferation, were purchased from Promega (USA). Murine tumor necro- sis factor-alpha (TNF- $\alpha)$ kits were purchased from Diaclone (France). PE-conjugated anti-mouse CD4 and APC-conjugated anti-mouse CD8a were purchased from eBioscience (USA). All other chemicals used were of analytical grade.

\subsection{Purification of the TVC protein}

All purification procedures were carried out at $4^{\circ} \mathrm{C}$ unless specified otherwise. Fresh fruiting bodies of $T$. versicolor $(1.0 \mathrm{~kg})$ were homogenized with $5 \mathrm{~L}$ of $25 \mathrm{mmol} \mathrm{L} \mathrm{L}^{-1}$ Tris/HCl buffer (v/v), $\mathrm{pH} 8.0$, in the presence of $0.1 \%(\mathrm{v} / \mathrm{v})$ 2-mercaptoethanol. The homogenate was centrifuged at $10000 \times g$ for $20 \mathrm{~min}$, and the supernatant was then precipitated by adding ammonium sulfate to $55 \%$ saturation. The precipitates were stirred overnight, and then collected by centrifugation at $20000 \times g$ for $30 \mathrm{~min}$. The pellets were dissolved in, and dialyzed against, $25 \mathrm{mmol} \mathrm{L}^{-1}$ Tris/ $\mathrm{HCl}$ buffer ( $\mathrm{pH}$ 8.0) for $48 \mathrm{~h}$ with five changes of dialysis buffer before application to a Q-Sepharose Fast Flow Column $(40 \mathrm{~mL})$ that had previously been equilibrated with the same buffer. The column was eluted to remove the unabsorbed fraction before applying a stepwise-elution with the same equilibrating buffer containing $0.1,0.25,0.4,0.55,0.8$ and $1.0 \mathrm{~mol} \mathrm{~L}^{-1} \mathrm{NaCl}$ at a flow rate of $2 \mathrm{~mL} \mathrm{~min}^{-1}$. The active fractions, as determined by the blast-formation stimulatory assay (as described in section 1.4), were pooled and concentrated by ultra filtration (Amicon, YM-3 membrane, cut-off $3 \mathrm{kD}$ ) and further purified on a Superdex G-75 column $(300 \mathrm{~mL})$ that had been pre-equilibrated using $25 \mathrm{mmol} \mathrm{L}^{-1}$ Tris/HCl buffer ( $\mathrm{pH}$ 8.0) supplemented with $0.15 \mathrm{~mol} \mathrm{~L}^{-1} \mathrm{NaCl}$. The same buffer was used as the mobile phase with a flow rate of $1 \mathrm{~mL} \mathrm{~min}^{-1}$. After elution with 1.2 times the column volume, the active fractions were identified as described above. A small peak, which eluted between two larger peaks, had the highest measured activity, and was collected and loaded onto a second Superdex G-75 column. The elution conditions used were the same as those described above. The most active fractions were pooled and subjected to electrophoresis (see section 1.3), which revealed a single protein band.

\subsection{Electrophoresis}

The purified protein was subjected to sodium dodecyl sulfate-polyacrylamide gel electrophoresis (SDS-PAGE) to determine the purity of the protein obtained by the purification protocol described above [21]. The gels were stained with Coomassie brilliant blue R-250, or with the periodic acid/Schiff staining technique to investigate the presence of carbohydrate-modified proteins [22]. An isoelectric focusing (IEF) assay was performed on precast PhastGel IEF $\mathrm{pH}$ 3.50-8.95 gels using a PhastSystem (Sweden) at $50 \mathrm{~V} \mathrm{~h}^{-1}$, following the manufacturer's instructions. 


\subsection{Blast-formation stimulatory assay}

Splenocytes of female BALB/c mice (6-8 weeks old) were dispersed with a syringe plunger. The cell suspension was then filtered through cell strainers, and the erythrocytes were lysed with $0.83 \%$ ammonium chloride lysis solution. Splenocytes were washed three times and resuspended in RPMI 1640 medium containing 10\% FBS. For the in vitro cell proliferation assay, cells $\left(500 \mu \mathrm{L}, 2 \times 10^{6}\right.$ cells $\left.\mathrm{mL}^{-1}\right)$ were stained with carboxyfluorescein succinimidyl ester (CFSE) and were stimulated with the purified TVC for $72 \mathrm{~h}$. Cultured splenocytes were analyzed using flow cytometry.

Human peripheral blood lymphocytes (hPBLs) in RPMI 1640 medium $\left(50 \mu \mathrm{L}, 5 \times 10^{5}\right.$ cells $\left.\mathrm{mL}^{-1}\right)$ were seeded into a 96-well plate and different concentrations of the purified TVC protein $\left(0-100 \mu \mathrm{g} \mathrm{mL}^{-1}\right)$ plus $5 \mu \mathrm{g} \mathrm{mL}^{-1}$ concanavalin $\mathrm{A}$ in $50 \mu \mathrm{L}$ phosphate buffered solution (PBS, $136 \mathrm{mmol}$ $\mathrm{L}^{-1} \mathrm{NaCl}, 2.7 \mathrm{mmol} \mathrm{L}^{-1} \mathrm{KCl}, 1.5 \mathrm{mmol} \mathrm{L}^{-1} \mathrm{KH}_{2} \mathrm{PO}_{4}$ and 8.0 mmol L ${ }^{-1} \mathrm{Na}_{2} \mathrm{HPO}_{4}$, pH 7.2) were added to the wells. After incubation of the cells at $37^{\circ} \mathrm{C}$ under an atmosphere containing $5 \% \mathrm{CO}_{2}$ for $68 \mathrm{~h}, 20 \mu \mathrm{L}$ of MTS solution was added. The cells were incubated for a further $4 \mathrm{~h}$ under the same conditions, and absorbance was then measured at $490 \mathrm{~nm}$ with a microplate reader (Bio-Rad model 680). The blank contained $100 \mu \mathrm{L}$ of culture medium, and the absorbance values of the samples were corrected by subtracting the absorbance value of the blank.

\subsection{Hemagglutination test}

Fresh red blood cells for monitoring hemagglutination activity were obtained from the eye pits of male rats. The blood was washed with PBS, centrifuged at $200 \times g$ for $10 \mathrm{~min}$, and then resuspended in PBS. After washing three times in PBS, the red blood cells were collected and suspended to $2 \%(\mathrm{v} / \mathrm{v})$ PBS. The purified TVC protein $(50 \mu \mathrm{L})$ was added to the red blood cell solution $(100 \mu \mathrm{L})$ to give final concentrations of $100.0 \mu \mathrm{g} \mathrm{mL}^{-1}, 50.0 \mu \mathrm{g} \mathrm{mL}^{-1}, 25.0$ $\mu \mathrm{g} \mathrm{mL}{ }^{-1}, 12.5 \mu \mathrm{g} \mathrm{mL}^{-1}$ and $6.3 \mu \mathrm{g} \mathrm{mL}^{-1}$ in the wells of a 96-well U-bottom plate, and then incubated at $37^{\circ} \mathrm{C}$. The degree of hemagglutination was determined after $2 \mathrm{~h}$.

\subsection{Measurement of nitrite accumulation}

The concentration of nitrite was measured with Griess reagent to evaluate NO production by macrophages. Macrophages RAW264.7 were cultured in 96-well plates for $4 \mathrm{~h}$, $37^{\circ} \mathrm{C}$. Lipopolysaccharide (LPS) $\left(2 \mu \mathrm{g} \mathrm{mL} \mathrm{m}^{-1}\right)$ and various amounts of TVC were added to give final concentrations between 0 and $8 \mu \mathrm{g} \mathrm{mL}^{-1}$, and the plates were incubated for a further $20 \mathrm{~h}$ under the same conditions. The culture supernatant was collected and nitrite concentrations were measured with Griess reaction kits, following the manufacturer's instructions. The nitrite concentration was determined by extrapolation based on a standard curve of sodium nitrite.

\subsection{Measurement of murine TNF- $\alpha$ by ELISA}

For evaluation of TNF- $\alpha$ production in culture media, macrophages RAW264.7 were incubated for $20 \mathrm{~h}$ with LPS $\left(2 \mu \mathrm{g} \mathrm{mL}{ }^{-1}\right)$ and various concentrations of TVC $(0-64 \mu \mathrm{g}$ $\left.\mathrm{mL}^{-1}\right)$ in 96-well culture plates. Cell-free cultures were obtained by centrifugation at $1000 \times g$ for $5 \mathrm{~min}$. The TNF- $\alpha$ content of the cell-free cultures was assessed by enzymelinked immunosorbent assay (ELISA) using commercially available kits, following the manufacturer's instructions. The TNF- $\alpha$ content was calculated from a standard curve for TNF- $\alpha$.

\subsection{N-terminal amino acid and MALDI-TOF mass spectrometry analyses of the purified protein}

For N-terminal amino acid sequencing, the purified TVC protein was separated by $15 \%$ SDS-PAGE and transferred to a polyvinylidene difluoride membrane (PVDF, Millipore, USA). Following excision of the appropriate band from the PVDF membrane, the N-terminal amino acid sequence of the protein was determined by the Edman degradation procedure using an automatic amino acid sequencer (Procise 492cLC, Applied Biosystems).

The protein was digested in-gel with trypsin and a peptide protein mass map was generated by matrix-assisted laser desorption/ionization time-of-flight (MALDI-TOF) mass spectrometry (MS, Biosystems Voyager 6192, ABI, USA), as described by Shevchenko et al. [23]. Database searching was performed using the monoisotopic peptide masses obtained from MALDI-TOF MS analysis. The SWISS-PROT and NCBI protein databases were searched with Mascot software. No restrictions on protein molecular weight, isoelectric point (pI), or species of origin were applied in the database searches.

\section{Results}

\subsection{Isolation and purification of TVC}

When subjected to Q-sepharose Fast Flow anion-exchange chromatography, the total protein mixture obtained from $T$. versicolor produced five elution peaks that absorbed at $280 \mathrm{~nm}$. The peak that showed the highest activity in a blastformation stimulatory assay was eluted with $25 \mathrm{mmol} \mathrm{L}^{-1}$ Tris/HCl (pH 8.0) plus $0.4 \mathrm{~mol} \mathrm{~L}^{-1} \mathrm{NaCl}$. The active fractions were pooled and subjected to gel filtration using a Superdex G-75 column. A small peak between two main peaks was observed in the elution profile. While this peak had activity towards hPBLs, the more abundant first eluted peak also showed some activity. SDS-PAGE analysis revealed that the small peak contained other proteins as minor con- 
taminants (data not shown). Fractions containing this small peak were therefore collected and subjected to a further round of Superdex G-75 chromatography. Fractions containing the third peak eluted (Figure 1) caused the greatest stimulation of hPBLs, and a single band was obtained by SDS-PAGE analysis (Figure 2A). We named this protein TVC. A total yield of $3 \mathrm{mg}$ of TVC was obtained from $1 \mathrm{~kg}$ of the fruiting body of $T$. versicolor.

\subsection{Characterization of TVC}

Various types of electrophoresis analysis were conducted to elucidate the biochemical characteristics of TVC. The purified TVC appeared as a single protein band with a molecular weight (MW) of $15 \mathrm{kD}$ in SDS-PAGE (Figure 2A). Native PAGE of TVC, however, revealed a single band with a $\mathrm{MW}$ of $30 \mathrm{kD}$ (Figure 2B), indicating that TVC exists as a homodimer in its natural form. IEF with buffers with $\mathrm{pH}$ values ranging from 3.50 to 8.95 showed that TVC is an acidic protein with a pI value of 4.0 (Figure $2 \mathrm{C}$ ). Negative staining of the polyacrylamide gel with periodic acid/Schiff reagent indicated that TVC is not modified with carbohydrate moieties (data not shown). The hemagglutination assay demonstrated that TVC does not agglutinate rat red blood cells at concentrations of up to $100 \mu \mathrm{g} \mathrm{mL} \mathrm{m}^{-1}$. Thus, the protein TVC lacks lectin characteristics.

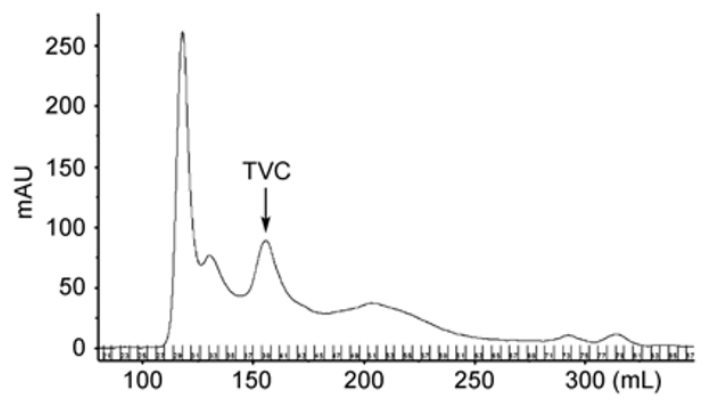

Figure 1 Elution profile of TVC from the second round of Superdex G-75 gel filtration chromatography.

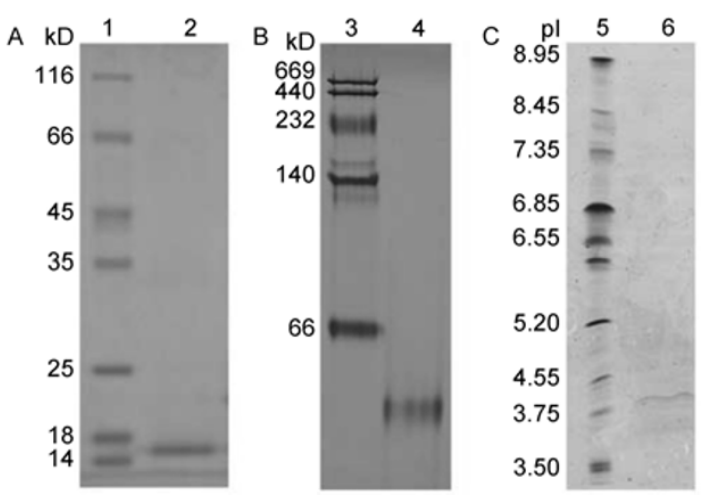

Figure 2 Electrophoretic analyses for purified protein TVC. A, Migration of TVC in SDS-PAGE. B, Migration of TVC in Native-PAGE. C, TVC was analyzed by IEF. Lanes 1 and 3, molecular weight marker; Lanes 2, 4 and 6, purified protein TVC; Lane 5, pI marker.

\subsection{TVC stimulates the proliferation of splenocytes and lymphocytes}

TVC's ability to promote the proliferation of mouse splenocytes was determined using flow cytometry (Figure $3)$. This showed that cell proliferation in the presence of anti CD3 and anti CD28 increased two-fold after incubation for $72 \mathrm{~h}$ when TVC $\left(10 \mu \mathrm{g} \mathrm{mL}^{-1}\right)$ was present. However, TVC had no stimulatory effect on cell proliferation of $\mathrm{CD} 4^{+}$and $\mathrm{CD}^{+} \mathrm{T}$ cells (data not shown).

In a blast-formation stimulatory assay, TVC alone or combined with concanavalin A induced hPBL cells to proliferate (Figure 4A). There was a significant correlation $(P<0.05)$ between the applied concentrations of TVC and the increase in numbers of hPBL cells, indicating that the TVC induced the proliferation of hPBLs in a dose-dependent manner. The highest proliferation of hPBLs observed was with $60 \mu \mathrm{g} \mathrm{mL}^{-1}$ of TVC. A synergistic effect was observed when both TVC and concanavalin A were supplemented.

\subsection{TVC enhances LPS-induced NO and TNF- $\alpha$ pro- duction by RAW 264.7 macrophages}

TVC significantly increased in vitro cellular NO production by LPS-activated RAW 264.7 macrophages. TVC concentrations from 0.5 to $2 \mu \mathrm{g} \mathrm{mL} \mathrm{m}^{-1}$ increased $\mathrm{NO}$ production by $15 \%-50 \%$ when compared with the control (Figure 4B). The increase occurred in a dose-dependent manner and activity was greatest at $2 \mu \mathrm{g} \mathrm{mL} \mathrm{m}^{-1}$ of TVC. TVC also significantly enhanced the accumulation of TNF- $\alpha$ in the culture of LPS-stimulated cells (Figure 4C). The effect was dosedependent, with the highest accumulation of TNF- $\alpha$ also occurring at a concentration of $2 \mu \mathrm{g} \mathrm{mL}^{-1} \mathrm{TVC}$. These results indicate that TVC synergistically promotes LPS-induced production of NO and TNF- $\alpha$ in macrophages.

\subsection{N-terminal amino acid and MALDI-TOF mass spectrometric analyses of TVC}

The sequence of N-terminal amino acid residues was determined as VAQLDTSKTSLTQN, which showed no signifi-

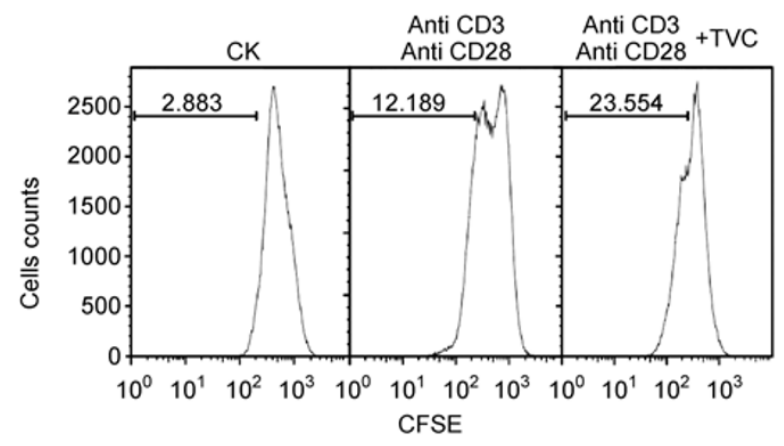

Figure 3 Histogram of CFSE stained mouse splenocytes. 

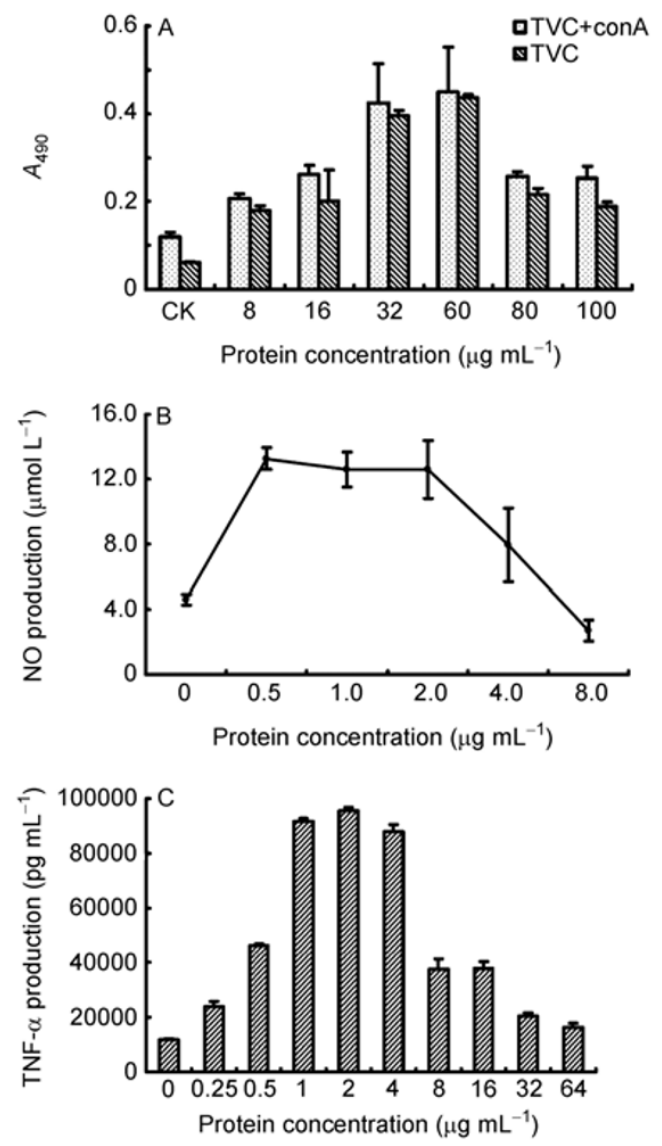

Figure 4 Biological activity assays of purified TVC protein. A, Effect of TVC and/or concanavalin A on the stimulation of human peripheral blood lymphocytes. B, Effect of TVC on nitrite accumulation in a culture of LPS-activated RAW 264.7 macrophages. C, Effect of TVC on TNF- $\alpha$ production in a culture of LPS-activated RAW 264.7 macrophages. All values are mean $\pm \mathrm{SE}, n=3$.

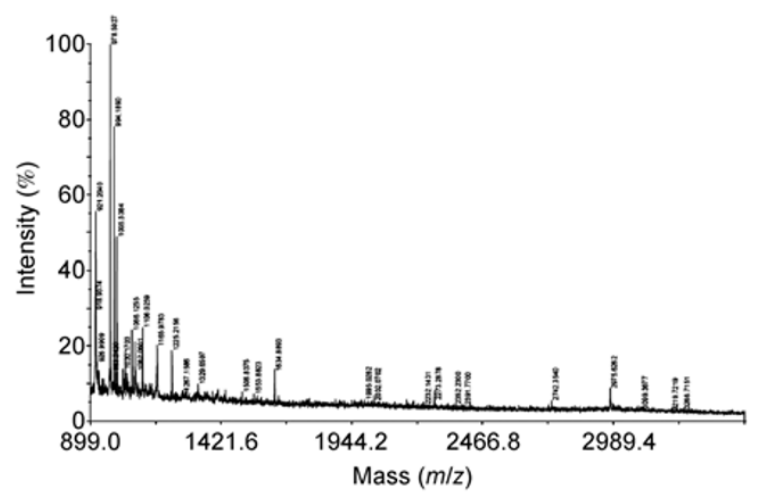

Figure 5 MALDI-TOF MS spectrum of purified protein TVC.

cant homology to any known protein by blast searching against SWISS-PROT and NCBI protein databases. The analysis of MALDI-TOF matrix compositions suggested that the top molecular weight search score was 48 for compositions, which is well below the threshold value of 80 (Figure 5). The protein reported here from T. versicolor is therefore a novel immunomodulatory protein.

\section{Discussion}

In previous studies, the crude extract of $T$. versicolor was shown to stimulate the proliferation of murine splenocytes in vitro, a similar effect to that seen with polysaccharide peptide (PSP) from $T$. versicolor on mouse $\mathrm{T}$ lymphocytes and splenocytes [24-27]. However, the active component in the crude extract was not determined in that study. The protein TVC, which was purified from $T$. versicolor for the first time in this study, has significant mitogenic activity for lymphocytes, splenocytes and stimulated the activity of macrophages. This newly discovered protein is therefore an active ingredient in $T$. versicolor and contributes to the medicinal effects of the fungus. The proliferative response induced by TVC is similar to that reported previously for other immunomodulatory proteins $[15,16,28]$. TVC shares other characteristics with previously reported immunomodulatory proteins, for example, TVC has a molecular weight of $15 \mathrm{kD}$, it is an acidic protein that is not modified with carbohydrates and it has no hemagglutination activity. These results indicate that TVC belongs to the family of fungal immunomodulatory proteins.

The fruiting bodies of $T$. versicolor are the structures that are observed in nature and used for medicine. Although we were able to extract immunomodulatory proteins from fruiting bodies of $T$. versicolor, the harvested yield TVC was low, with polysaccharides making up most of the mass of the fruiting bodies [29]. We therefore grew the fungus in submerged culture to harvest large quantities of mycelial biomass for protein extraction.

Our results suggest that there is an optimal concentration at which TVC exerts stimulatory effects on immune cells, with inhibition observed at higher and lower concentrations. The inhibitory effect observed at high concentrations may result from saturation of signal molecule transduction. These concentration effects may hinder identification of the immunomodulatory protein during protein isolation and purification, especially in the first purification step of gel filtration chromatography. It is possible that the first large peak observed in the gel filtration profile contained a low concentration of high activity TVC, while the smaller peak chosen for further study may have contained a high concentration of lower activity TVC.

Nitric oxide is not only considered to be a signal molecule but also a functional agent that protects cells in many biological responses. Nitric oxide plays a key role in mediating macrophage cytotoxicity toward different targets, including tumor cells and intracellular pathogens [30]. Nitric oxide production has been frequently used to measure immunomodulatory activity. While many researchers have reported that nitric oxide production can be affected by mushroom polysaccharides, little is known about how nitric 
oxide production is affected by mushroom proteins. Pang et al. [31] showed that nitric oxide production was much higher when mouse peritoneal macrophages were treated with LPS in the presence of polysaccharide Krestin than with LPS alone. Our studies have shown that TVC is not a glycoprotein, and yet can promote nitric oxide production and therefore has the same functions previously reported for polysaccharides. This result shows that TVC is a regulatory factor that induces nitric oxide synthase synthesis resulting in the generation of large amounts of nitric oxide by macrophages.

Cytokines are small proteins or peptides that are secreted by immune cells that mediate and regulate immunity, inflammation and transmit information between cells. The ability to enhance production and accumulation of cytokines by some immune cells has been widely used as an in vitro experimental indicator of immunomodulatory activity of fungal preparations. Tumor necrosis factor, originally discovered as a factor with extraordinary antitumor activity, is an endogenous pro-inflammatory cytokine [32]. In this study, TVC with LPS, but not TVC alone, significantly increased TNF- $\alpha$ secretion by macrophages. Although Toll-like receptor 4 (TLR4), a transmembrane component of the LPS signal transduction complex, promotes the production of NO and TNF- $\alpha$ in macrophages [33-35], it does not seem to be the direct ligand of TVC. The synergistic activity of TVC, i.e., the stimulation of NO/TNF- $\alpha$ production by LPS-induced macrophages, also suggests that TVC enhances the expression of downstream mediators that are generated by LPS activation and the TLR4 pathway. TVC and the endotoxin LPS of E. coli can synergistically enhance NO accumulation and TNF- $\alpha$ production by macrophages RAW 264.7, which suggests that TVC can also enhance the activity of Natural Killer cells and activate endothelial cells and macrophages. The synergistic effect on proliferation of hPBL cells induced by TVC and concanavalin A indicates that the target cells of TVC may be similar to those of concanavalin A. Therefore, we speculate that TVC may modulate host immune responses in vivo and so may have value in treating various diseases. The molecular mechanisms underlying TVC activity and the effects of TVC on human physiology and health warrant further investigation.

This work was supported by the National High Technology Research and Development Program of China (Grant No. 2007AA021506). We thank the $R \& D$ Centre of Novozymes China for providing research facilities for protein purification.

1 Chu K K, Ho S S, Chow A H. Coriolus versicolor: A medicinal mushroom with promising immunotherapeutic values. J Clin Pharmacol, 2002, 42: 976-984

$2 \mathrm{Ng} \mathrm{T} \mathrm{B.} \mathrm{A} \mathrm{review} \mathrm{of} \mathrm{research} \mathrm{on} \mathrm{the} \mathrm{protein-bound} \mathrm{polysaccharide}$ (polysaccharopeptide, PSP) from the mushroom Coriolus versicolor (Basidiomycetes: Polyporaceae). Gen Pharmacol, 1998, 30: 1-4

3 Zaidman B Z, Yassin M, Mahajna J, et al. Medicinal mushroom modulators of molecular targets as cancer therapeutics. Appl Microbiol Biotechnol, 2005, 67: 453-468

4 Wang H X, Ng T B, Ooi V E C. Lectins from mushrooms. Mycol Res, 1998, 102: 897-906

5 Wang H X, Liu W K, Ng T B, et al. The immunomodulatory and antitumor activities of lectins from the mushroom Tricholoma mongolicum. Immunopharmacology, 1996, 31: 205-211

6 Wang H X, Gao J Q, Ng T B. A new lectin with highly potent antihepatoma and antisarcoma activities from the oyster mushroom Pleurotus ostreatus. Biochem Biophys Res Commun, 2000, 275: 810-816

7 Ikekawa T, Maruyama H, Miyano T, et al. Proflamin, a new antitumor agent-preparation, physicochemical properties and antitumor-activity. Jpn J Cancer Res, 1985, 76: 142-148

8 Moradali M F, Mostafavi H, Ghods S, et al. Immunomodulating and anticancer agents in the realm of macromycetes fungi (macrofungi). Int Immunopharmacol, 2007, 7: 701-724

9 Tanaka S, Ko K, Kino K, et al. Complete amino acid sequence of an immunomodulatory protein, Ling Zhi-8 (LZ-8). An immunomodulator from a fungus, Ganoderma lucidium, having similarity to immunoglobulin variable regions. J Biol Chem, 1989, 264: 16372-16377

10 Haak-Frendscho M, Kino K, Sone T, et al. Ling Zhi-8: A novel T cell mitogen induces cytokine production and upregulation of ICAM-1 expression. Cell Immunol, 1993, 150: 101-113

11 van der Hem L G, van der Vliet J A, Bocken C F, et al. Ling Zhi-8: Studies of a new immunomodulating agent. Transplantation, 1995, 60: 438-443

12 Miyasaka N, Inoue $\mathrm{H}$, Totsuka $\mathrm{T}$, et al. An immunomodulatory protein, Ling Zhi-8, facilitates cellular interaction through modulation of adhesion molecules. Biochem Biophys Res Commun, 1992, 186: 385-390

13 Kino K, Mizumoto K, Sone T, et al. An immunomodulating protein, Ling Zhi-8 (LZ-8) prevents insulitis in non-obese diabetic mice. Diabetologia, 1990, 33: 713-718

14 Kino K, Sone T, Watanabe J, et al. Immunomodulator, LZ-8, prevents antibody production in mice. Int J Immunopharmacol, 1991, 13: 1109-1115

15 Ko J L, Hsu C I, Lin R H, et al. A new fungal immunomodulatory protein, FIP-fve isolated from the edible mushroom, Flammulina velutipes and its complete amino acid sequence. Eur J Biochem, 1995, 228: 244-249

16 Hsu H C, Hsu C I, Lin R H, et al. Fip-vvo, a new fungal immunomodulatory protein isolated from Volvariella volvacea. Biochem $\mathrm{J}$, 1997, 323: 557-565

17 Lin W H, Hung C H, Hsu C I, et al. Dimerization of the N-terminal amphipathic alpha-helix domain of the fungal immunomodulatory protein from Ganoderma tsugae (Fip-gts) defined by a yeast two-hybrid system and site-directed mutagenesis. J Biol Chem, 1997, 272: 20044-20048

18 Sheu F, Chien P J, Chien A L, et al. Isolation and characterization of an immunomodulatory protein (APP), from the Jew's Ear mushroom Auricularia polytricha. Food Chem, 2004, 87: 593-600

19 Sheu F, Chien P J, Wang H K, et al. New protein PCiP from edible golden oyster mushroom (Pleurotus citrinopileatus) activating murine macrophages and splenocytes. J Sci Food Agri, 2007, 87: 15501558

20 Strong D M, Ahmed A A, Thurman G B, et al. In vitro stimulation of murine spleen cells using a microculture system and a multiple automated sample harvester. J Immunol Methods, 1973, 2: 279-291

21 Laemmli U K. Cleavage of structural proteins during the assembly of the head of bacteriophage T4. Nature, 1970, 227: 680-685

22 Zacharius R M, Zell T E, Morrison J H, et al. Glycoprotein staining following electrophoresis on acrylamide gels. Anal Biochem, 1969, 30: $148-152$

23 Shevchenko A, Wilm M, Vorm O, et al. Mass spectrometric sequencing of proteins from silver stained polyacrylamide gels. Anal Chem, 1996, 68: 850-858

24 Wang H X, Ng T B, Liu W K, et al. Polysaccharide-peptide complexes from the cultured mycelia of the mushroom Coriolus versi- 
color and their culture medium activate mouse lymphocytes and macrophages. Int J Biochem Cell B, 1996, 28: 601-607

25 Wang $\mathrm{H} \mathrm{X}$, Liu W K, Ng T B, et al. Immunomodulatory and antitumor activities of a polysaccharide-peptide complex from a mycelial culture of Tricholoma sp., a local edible mushroom. Life Sci, 1995, 57: 269-281

26 Wong C K, Tse P S, Wong E L, et al. Immunomodulatory effects of yun zhi and danshen capsules in health subjects-a randomized, double-blind, placebo-controlled, crossover study. Int Immunopharmacol, 2004, 4: 201-211

27 Lau C B, Ho C Y, Kim C F, et al. Cytotoxic activities of Coriolus versicolor (Yunzhi) extract on human leukemia and lymphoma cells by induction of apoptosis. Life Sci, 2004, 75: 797-808

28 Kino K, Yamashita A, Yamaoka K, et al. Isolation and characterization of a new immunomodulatory protein, Ling Zhi-8 (LZ-8), from Ganoderma lucidium. J Biol Chem, 1989, 264: 472-478

29 Tsukagoshi S, Hashimoto Y, Fujii G, et al. Krestin (PSK). Cancer
Treat Rev, 1984, 11: 131-155

30 Carreras M C, Poderoso J J, Cadenas E, et al. Measurement of nitric oxide and hydrogen peroxide production from human neutrophils. Methods Enzymol, 1996, 269: 65-75

31 Pang Z J, Zhou M, Chen Y, et al. A protein-bound polysaccharide synergistic with lipopolysaccharide induces nitric oxide release and antioxidant enzyme activities in mouse peritoneal macrophages. Am J Chin Med, 1998, 26: 133-141

32 Aggarwal B B, Natarajan K. Tumor necrosis factors: Developments during the last decade. Eur Cytokine Netw, 1996, 7: 93-124

33 Beutler B, Du X, Poltorak A. Identification of Toll-like receptor 4 (Tlr4) as the sole conduit for LPS signal transduction: Genetic and evolutionary studies. J Endotoxin Res, 2001, 7: 277-280

34 Yang Q, Zhu P, Wang Z, et al. Toll-like receptor 4, a novel signal transducer for lipopolysaccharide. Chin J Traumatol, 2002, 5: 55-58

35 Goldstein D R. Toll-like receptors and other links between innate and acquired alloimmunity. Curr Opin Immunol, 2004, 16: 538-544

Open Access This article is distributed under the terms of the Creative Commons Attribution License which permits any use, distribution, and reproduction in any medium, provided the original author(s) and source are credited. 